DOI: $10.17223 / 22220836 / 24 / 20$

\title{
С.Ю. Щетинина
}

\section{СОВРЕМЕННЫЕ МУЛЬТИМЕДИЙНЫЕ ТЕХНОЛОГИИ ПРЕЗЕНТАЦИИ ПРОИЗВЕДЕНИЙ ИСКУССТВА}

\begin{abstract}
В статье рассматриваются мультимедийные технологии в качестве средств презентации произведений искусства в художественной экспозиции на территории крупнейших музеев и исследовательских иентров мира. Описываются технологические достижения и тенденции в оснащении художественных экспозиций, функциональные возможности и особенности выразительных средств мультимедийных технологий. Рассматривается специфика художественного восприятия произведений, показанных зрителю с использованием мультимедийных технологий.

Ключевые слова: мультимедийные технологии, мобильные приложения, экспозиция, художественное восприятие, интерактивность.
\end{abstract}

В современном искусствознании растет интерес к различным технологическим новшествам, которые осваиваются художниками, и мультимедийные технологии - одно из них. Мультимедиа является средством «предоставления информации с помощью объединения множества воспринимаемых человеком сред (аудиальное, визуальное и кинестетическое воздействие), управляемых интерактивным программным обеспечением» [1. С. 25]. Изобразительновыразительные средства, характерные для мультимедиа, обладают уникальной особенностью - интерактивностью и специфической эстетической природой, в которой объединены пространством и временем художественные средства и материалы [2. С. 18].

Технологические достижения современности оказали влияние на стиль и формы мышления в среде искусства, породив новые способы взаимодействия с ним. Доступность мультимедийных устройств большому количеству людей в повседневной жизни со временем сделала их часто используемыми и изменила восприятие визуальной реальности. Зрительная погруженность во взаимодействие с экраном монитора, планшета, телефона, вовлеченность в глобальную Сеть повлияли на возможности эстетического и психологического восприятия зрительных образов.

Одно из направлений применения технологии мультимедиа - презентация произведений искусства, ставших историческим наследием, посредством чего такие произведения актуализируются и обретают новое звучание. Другая область применения мультимедиа проявляется в качестве инструмента художественной выразительности в современных художественных практиках, таких как перформанс и инсталляция. В данной статье приведены практические примеры применения мультимедиа как технологии презентации классического искусства и как выразительного средства перформанса.

Современные мультимедийные технологии играют большую роль в передаче и актуализации культурного наследия художественных музеев. Наиболее оснащенными технологическими средствами являются выставочные 
площадки и музеи развитых стран: музей МоМа, Нью-Йорк, США; музей искусства GALLERY ONE, Кливленд, США; центр искусств и медиатехнологий в Карлсруэ (ZKM), Германия; Экспериментальный центр медиаискусства и перформанса (Experimental Media and Performing Arts Center), Нью-Йорк, США. В области разработки и внедрения технологий ведущую роль играют Городской университет Гонконга (City University of Hong Kong, CityU), Гонконг, КНР; Центр исследований интерактивного кино (The iCinema Centre for Interactive Cinema Research), Сидней, Австралия. Остановимся на некоторых технологических достижениях перечисленных выставочных и научных центров.

Рассмотрим ряд функциональных возможностей мультимедийных устройств, а именно мультимедийную мобильную навигацию. Мобильное приложение, расширяющее взаимодействие с коллекцией искусства, использует музей МоМа в Нью-Йорке. Мобильное приложение позволяет зрителю, вопервых, составить пространственное представление о границах и тематических разделах, уровнях экспозиции; во-вторых, заранее определиться в предпочтениях и спланировать посещение; в-третьих, сделать интерактивную метку «на карте» экспозиции, сопроводив ее персональной информацией, и открыть доступ участникам сетевых сообществ. Приложение содержит поэтажные планы здания музея с обозначением текущих выставок на этажах, выставки в приложении представлены иллюстрациями экспонатов, текстовой, видео- и аудиоинформацией о них.

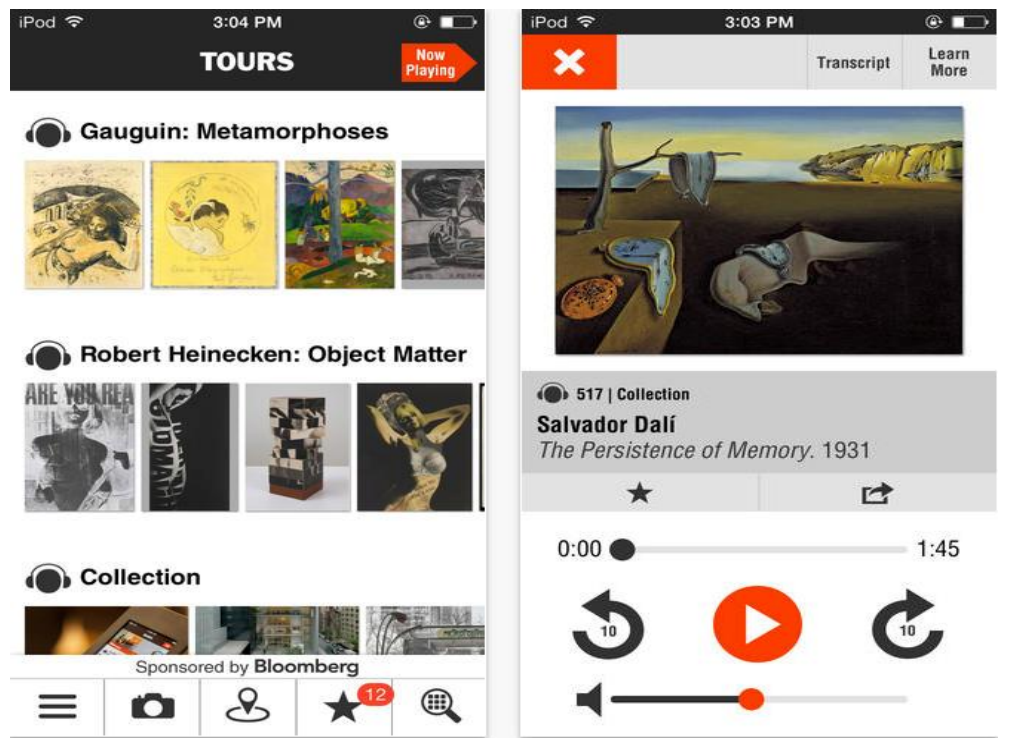

Мобильное приложение музея МоМа, Нью-Йорк, США

В результате применения мобильного приложения восприятие экспозиционного пространства расширяется большим охватом его глубины и границ, предварительным выбором приоритетных мест, возможностью сообщить об этих местах другим зрителям в реальном времени или в дальнейшем. Мобильное приложение предварительно информирует о произведениях на вы- 
ставке, мотивируя зрителей к посещению музея. Особенностью данной технологии является возможность получения статистических данных о посещениях выставок, так как программа фиксирует количество обращений к определенным экспонатам и обеспечивает обратную связь со зрителями, так как они отмечают и формируют «собственную» коллекцию фотоснимков произведений искусства.

Кроме того, данное мобильное приложение дополняет художественное восприятие звуковым сопровождением. В аудиоописание картин и биографий художников включен профессиональный многоголосый закадровый дубляж (отдельно для детей и взрослых), способствующий погружению в атмосферу произведения. Звуковое сопровождение реализовано в двух вариантах: в виде функции «аудиотур» (которым можно воспользоваться, не находясь в музее), а также в виде функции «визуальный анализ» произведения. «Визуальный анализ» позволяет прослушать голосовое описание картин с детальной характеристикой изображения, в которой виртуальный посетитель видит репродукцию и слышит визуальный анализ полотна, представленный профессиональным искусствоведом.

Использование мобильных устройств и приложений к ним в целях обучения носит персонифицированный характер и совместимо с индивидуальными познавательно-образовательными задачами зрителя. Обучение с помощью мультимедийных приложений ориентировано на специальное изучение разделов истории искусства, стилей, жанров без участия специалиста (экскурсовода).

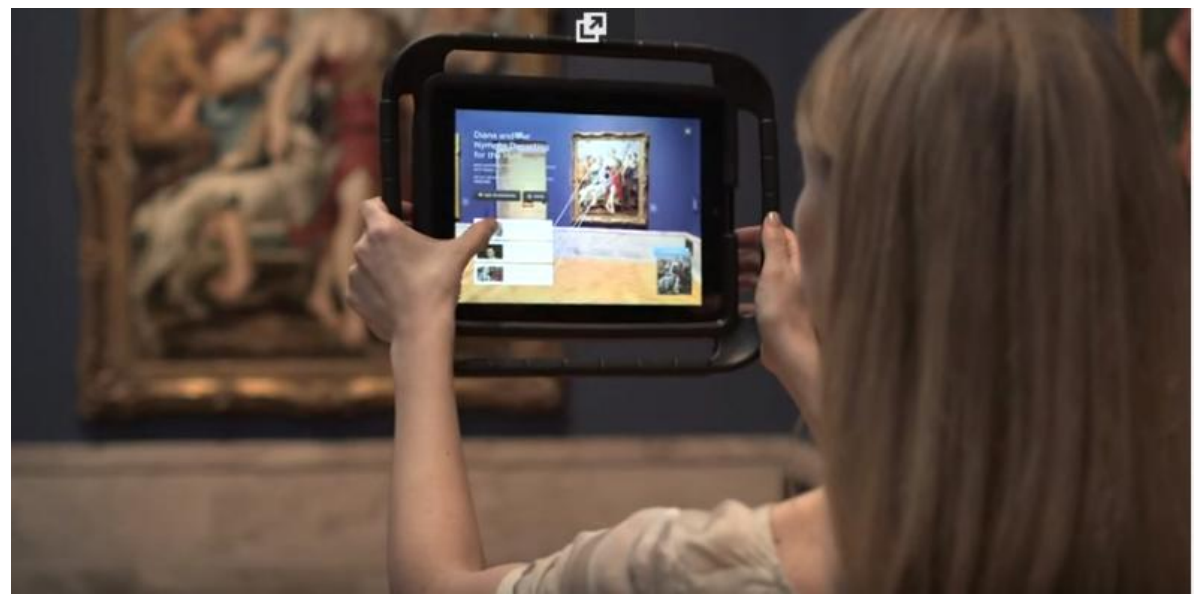

Мобильное приложение музея GALLERY ONE, Кливленд, США

Другое мобильное приложение нацелено на изучение предмета искусства и взаимодействие с ним, оно разработано для музея GALLERY ONE в Кливленде, США. Технология дает возможность зрителю более активно взаимодействовать с произведением, быстро различать его в ряде других, в том числе в исторической перспективе. В процессе взаимодействия с экспонатом через мобильное приложение зритель имеет возможность совершать различные игровые и познавательные манипуляции: узнать о героях, изображенных на картине, или историю ее создания, собрать изображение фрески самостоя- 
тельно по частям. Технические устройства предоставляют информацию зрителю разными способами: на мультимедийной интерактивной стене, где можно выбрать направление изучения по репродукции или периоду истории; на переносных информационных интерактивных панелях, размещенных непосредственно рядом с экспонатом; в форме мобильных устройств, работающих совместно с приложениями к ним. Информационные интерактивные панели сопровождают экспонаты исторической справкой, искусствоведческим анализом произведения, дополнительными иллюстрациями и другими материалами.

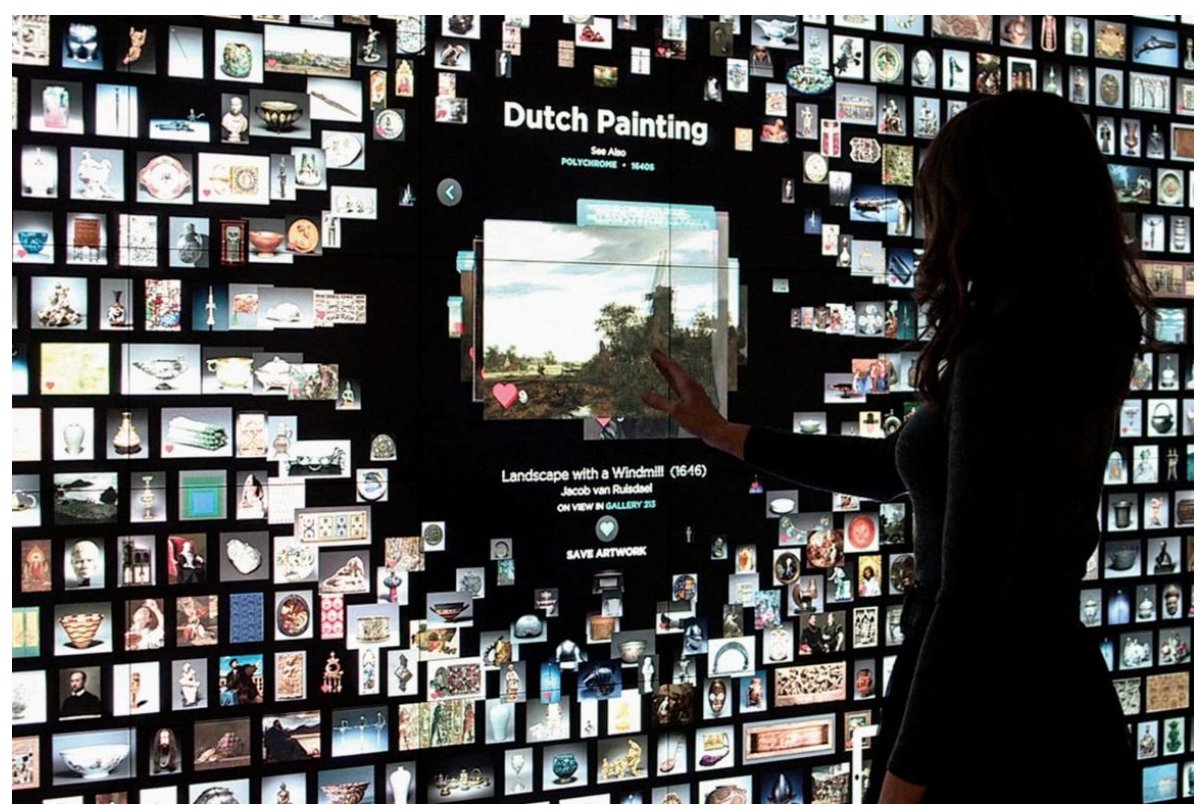

Мультимедийная интерактивная стена в музее GALLERY ONE, Кливленд, США

Функции расширенного восприятия произведений существенно улучшают запоминание информации об артефактах при взаимодействии с ними посредством мультимедийного устройства, однако специфической чертой такой формы художественного восприятия является его запрограммированный сценарий. Акт художественной коммуникации заведомо определен, результат прочтения произведений записан, зрителю остается усвоить материал, что, вероятно, может ограничивать самостоятельную зрительскую активность.

Художественная коммуникация изменяется с включением в нее мультимедийных устройств-посредников. Благодаря применению мобильных устройств и мультимедиа зрительские впечатления от взаимодействия с объектами искусства становятся направленными и конкретными с точки зрения их интерпретации.

Технологии позволяют передать стратегии прочтения, разработанные знатоками искусства, «профессиональное видение» напрямую зрителю [3. C. 23]. Так, например, специальное приложение интерактивной галереи GALLERY ONE дает расширенную возможность коммуникации: возмож- 
ность повторить визуальные очертания образа в графической зарисовке на планшете, сымитировать позу скульптуры или эмоцию, запечатленную в ней, сохранить репродукцию в мобильное устройство. Перечисленные интерактивные опции способствуют интенсификации вовлеченности в процесс художественной коммуникации зрителя и произведения искусства [4].

Таким образом, использование мультимедийных мобильных устройств существенно дополняет реальность непосредственного художественного восприятия произведений искусства: навигацией в пространстве галереи, индивидуальной стратегией коммуникации с искусством. Далее рассмотрим другой тип технологий в художественной экспозиции - панорамные интерактивные экраны. Экран создается для большего охвата массива визуальной информации и выделения необходимой ее части зрителем.

Практическим применением такой технологии в выставочном пространстве занимается крупнейший в мире Центр искусств и медиатехнологий, основанный в 1997 г. в г. Карлсруэ, Германия (Zentrum für Kunst und Medientechnologie, ZKM). Центр интегрирует достижения в технике и искусстве, объединяет выставочную и научную деятельность, является площадкой мультимедиа технологий, а также размещает художественные проекты, разработанные Институтом визуальных медиа (Institute of Visual Media), pacположенным при центре. Институт разрабатывает и внедряет в практику передовые технологии мультимедиа, здесь можно познакомиться с ними до их массового распространения.

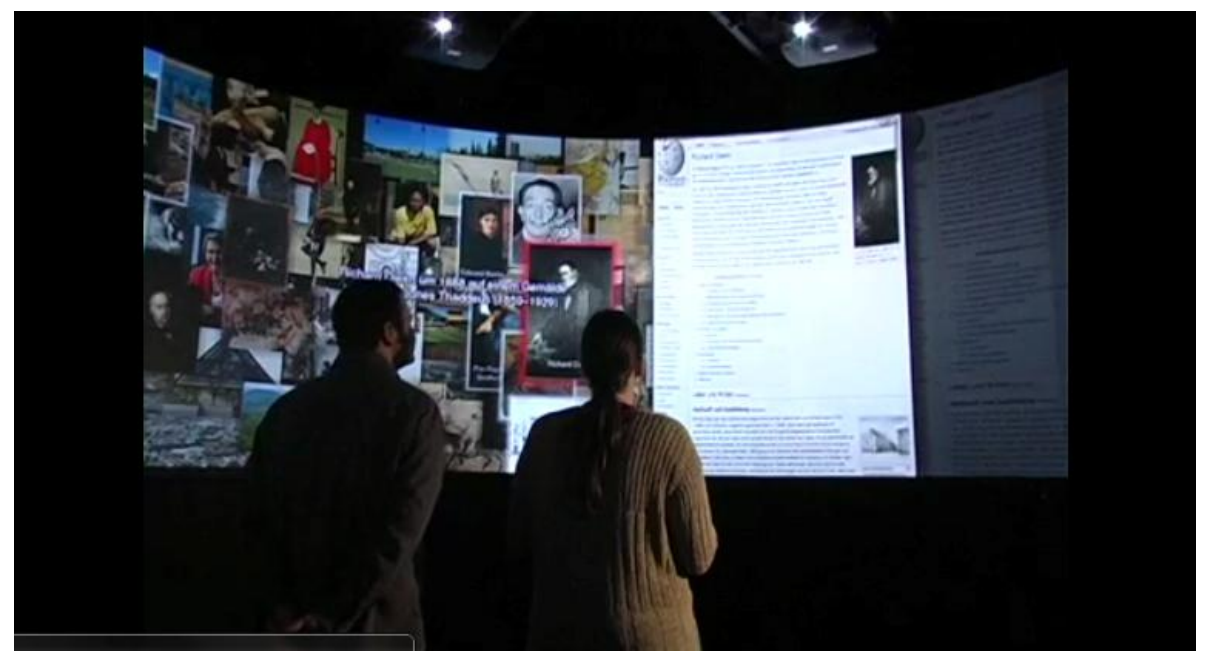

Интерактивная информационная панорама, ZKM, Карлсруэ, Германия

Инновационным устройством, входящим в оснащение художественных проектов в центре ZKM, является интерактивная демонстрационная панорама высокого разрешения (Interactive High Resolution Panorama), которая предоставляет визуализацию информации для зрителя с интерактивным содержанием и возможностью манипуляций с ней в реальном времени. Информационное содержание панорамы представлено репродукциями, иллюстрациями в сопровождении с текстами и используется в образовательных целях. 
Другое ее применение как части инсталляции или интерактивного перформанса используется художниками, и в их проектах мультимедийная панорама является особенным выразительным средством. Как выразительное средство, этот объект привносит уникальные возможности в инсталляцию: кинетические эффекты, сферическую панорамную обзорность и объемность видеоизображений, что в сумме усиливает визуальное воздействие [5] и синхронизирует его со звуковым и осязаемым воздействием на зрителя.

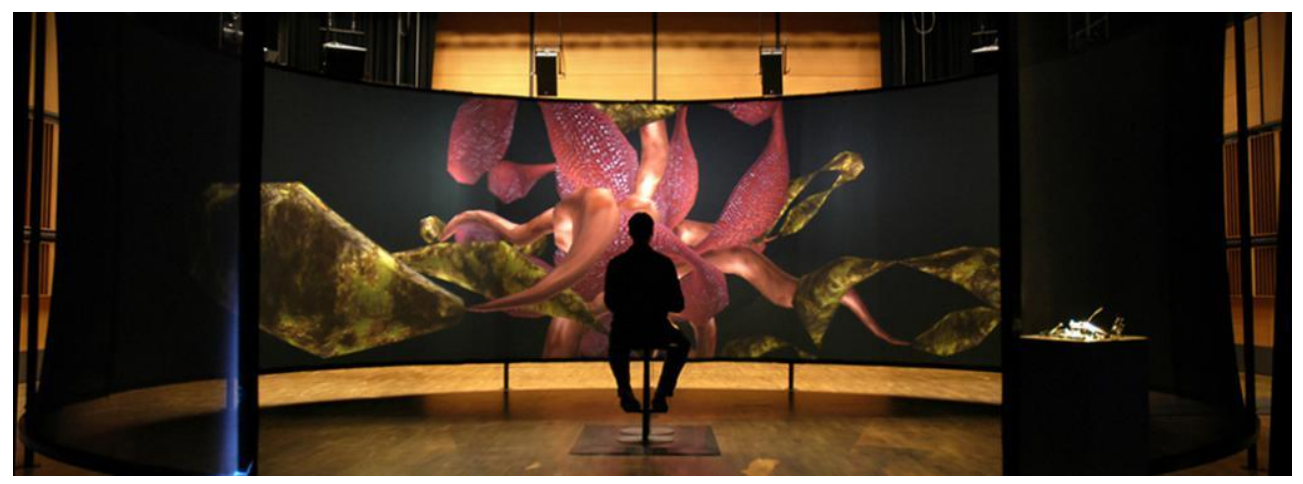

Интерактивная демонстрационная панорама, ZKM, Карлсруэ, Германия

Характерными особенностями интерактивной панорамы являются ее большой размер (по сравнению с человеческим телом), геометрия и размещение в пространстве (изогнутая форма, охватывающая внимание зрителя внутри себя), а также интерактивность. Можно предположить, что особенности такого устройства влияют на зрительное восприятие, которое расширяется до восприятия телесного.

Справочная информация с интерактивной панорамы усваивается с помощью мобильного планшета или телефона, предоставляя зрелищную подачу зрителю, однако если речь идет об изобразительном восприятии, вероятно, утрачивается непосредственное созерцание оригинального размера изображаемого, пропорции существенно искажаются. Художественное восприятие визуальных образов, переданных интерактивной панорамой, меняется, интенсифицируется, становится фрагментарным и динамичным.

Экспериментальный центр медиаискусства и перформанса (Experimental Media and Performing Arts Center) в Нью-Йорке, США, занимается изучением и внедрением передовых устройств и технологий в деятельность художников. Центр поддерживает эксперименты в работе с пространственными эффектами: световыми, звуковыми и музыкальными, мультимедийными экранными и другими - и соединении их в единую композицию.

На выставочной площадке центра в перформансе «Сверх Формы» (Extra Shapes) художники экспериментируют с мультимедийным содержанием художественного решения. Перформанс состоит из сочетания различных средовых инструментов и использует идеи созерцания и восприятия движения света, звука, видео, танца и других сред. Произведение исследует спонтанность, функционирование и восприятие сред зрителем, превращая их взаимодействие в живой интерактивный процесс. 


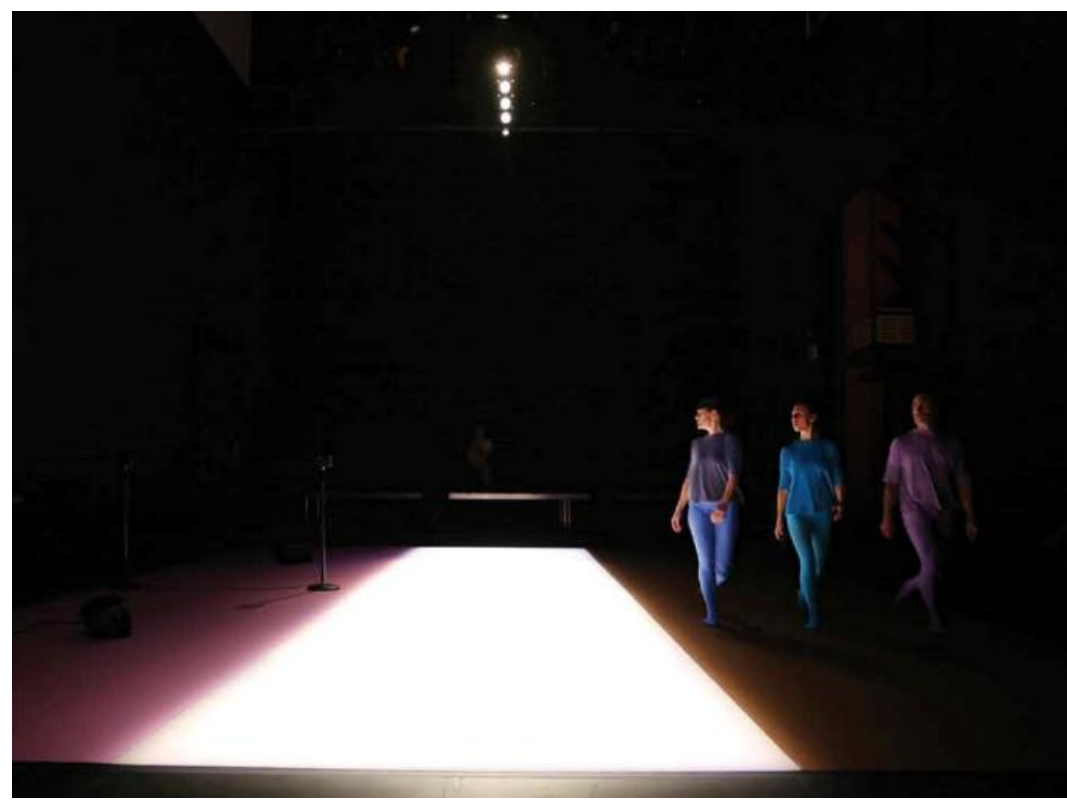

Перформанс «Сверх Формы» в Экспериментальном центре медиаискусства и перформанса, Нью-Йорк, США

Данный пример перформанса показывает, как современные технологии осваиваются художниками через необычное сочетание средовых инструментов и создание пространства, в котором они выражают свои идеи и приглашают зрителя для проживания этих идей. Инструментами для художника являются не привычные кисть и холст, не планшет и компьютер, а специфически средовые: звук, луч света, движение, видео, исполнение танца, различные механизмы в пространстве и др.

Подводя итог обзору функциональных возможностей мультимедийных устройств, отметим их разновидностями в художественной экспозиции: планшеты, персональные телефоны, навигаторы, интерактивные экраны, панорамы и др. Мобильные устройства и приложения к ним обширно используются в процессе художественной коммуникации с произведениями искусства галерей и музеев. Применение устройств в экспозиции выставочного пространства способствует расширению информационного представления об организованной в этом пространстве реальности, дает дополнительные возможности художественного восприятия. Технологии мультимедиа соединяют несколько видов чувственного восприятия в один поток, транслируют по выбору зрителя видео-, звуковое или текстовое содержание. Технология мультимедиа воздействует одновременно на несколько каналов восприятия [6], однако виртуализация художественного восприятия носит двойственный характер: с одной стороны, актуализирует произведение, с другой способствует утрате уникальности восприятия оригинала произведения. Технология мультимедиа является посредником, который управляет художественным восприятием и не оставляет места уникальному прочтению произведения искусства у зрителя. 
В заключение отметим, что современные технологии презентации расширяют художественную реальность, углубляют взаимодействие со зрителем, обогащают художественную образность, раскрывая его новые границы. Виртуальность и мультимедийность включены в восприятие современного человека, живущего отчасти в среде Интернета, социальных сетей, 4D фильмов и других технологий. Сегодня мультимедиа-технологии в искусстве являются синтетическим единством визуальных, аудиальных, кинестетических и других множественных компонентов, функционирующих в управляемой художником среде. Учитывая эти особенности выразительных средств и способности мультисенсорного восприятия у зрителя, вероятно, традиционная презентация произведений искусства требует переосмысления и включения технологических новшеств в художественную коммуникацию.

\section{Лuтература}

1. Шльккова О.В. Культура мультимедиа. М. : ФАИР-ПРЕСС, 2004. 415 с.

2. Дворко Н.И. Основы режиссуры мультимедиа-программ / Н.И. Дворко, В.Ф. Познин, И.Р. Кузнецов, А.Е. Каурых. СПб. : СПбГУП, 2005. 313 с.

3. Angeles Munoz Civantos. Using mobile media creation to structure museum interpretation with professional vision // Angeles Munoz Civantos, Michael Brown, Tim Coughlan, Shaaron Ainsworth, Katharina Lorenz [Электронный pecypc]. URL: http://dl.acm.org/citation.cfm?id=2896643 (дата обращения: 01.06.2016).

4. Falk J.H. Understanding Museum Visitors' Motivations and Learning. Museums as social learning spaces. 2013. P. 188-208.

5. Арнхейм Р. Искусство и визуальное восприятие. М. : Прогресс, 1974. 392 с.

6. Психология зрительного восприятия / В.Т. Прокопенко, В.А. Трофимов, Л.П. Шарок. СПб. : СПбГУИТМО, 2006. 73 с.

Shchetinina Svetlana Ju. Novosibirsk State University of Architecture, Design and Arts (Novosibirsk, Russian Federation).

E-mail: shine3@ngs.ru

Tomsk State University Journal of Cultural Studies and Art History, 2016, (4) 24; 185-193.

DOI: $10.17223 / 22220836 / 24 / 20$

WORKS OF ART MODERN MULTIMEDIA PRESENTATION TECHNOLOGIES ity.

Key words: multimedia technologies, mobile application, exposition, arts perception, interactiv-

Use of modern technologies in Art Science becomes more popular among artists day after day and multimedia technologies are one of them. Technological innovations of today influenced the way and form of thinking in art and created new ways of interaction with it.

Exhibition spaces and museums in advanced countries are equipped in the best ways: MoMa museum New York; Gallery One The Cleveland Museum of Art; ZKM Center for Art and Media Karlsruhe; Experimental Media and Performing Arts Center New York; City University of Hong Kong; The iCinema Centre for Interactive Cinema Research Sydney.

Multimedia mobile navigation in the MoMa museum is able to produce statistics data concerning exhibitions visits, and enhanced artistic perception of art objects (audio tour and visual analysis of a work of art).

Gallery One Cleveland Museum of Art mobile app gives the spectator a possibility to learn the story of the characters depicted and the story of the artwork creation, to unite small parts to get complete picture, to obtain historical information, art history analysis, additional illustrations and other materials.

Panoramic interactive screen in the Center for Art and Media Karlsruhe Germany is made for a larger visual coverage and provides visual information to the spectator interactively, giving a possibility to manipulate it in real time. Interactive panorama is also used by artists as an expressive means for their installations and performances.

Combinations of various environmental instruments and the contemplation of ideas and perception of their differences are investigated on the Experimental Media and Performing Arts Center exhi- 
bition space. «Extra Shapes» project explores spontaneity, functioning and the spectator's perception of environmental effects: light, sound, video, dance, etc.

Modern multimedia presentation technologies expand the artistic reality, deepen interaction with the audience, enrich the artistic imagery revealing its new borders. Multimedia art technologies create synthetic unity of visual, auditory, kinesthetic and other components running within controlled environment. But still, there are pros and cons for virtualization of artistic perception of traditional art in a museum: on the one hand it updates the work of art, on the other hand it promotes loss of its unique character perception. The technology is a mediator, which partially controls artistic perception.

\section{References}

1. Shlykova, O.V. (2004) Kul'tura mul'timedia [Multimedia Culture]. Moscow: FAIR-PRESS.

2. Dvorko, N.I., Poznin, V.F., Kuznetsov, I.R. \& Kaurykh, A.E. (2005) Osnovy rezhissury mul'timedia-programm [Fundamentals of directing multimedia programs]. St. Petersburg: St. Petersburg University of the Humanities and Social Sciences.

3. Civantos, A.M., Brown, M., Coughlan, T., Ainsworth, Sh. \& Lorenz, K. (2016) Using mobile media creation to structure museum interpretation with professional vision. Personal and Ubiquitous Computing. 20(1). [Online] Available from: http://dl.acm.org/citation.cfm?id=2896643. (Accessed: 1 st June 2016). DOI: 10.1007/s00779-015-0895-3

4. Falk, J.H. (2013) Understanding Museum Visitors' Motivations and Learning .In: Brændholt Lundgaard, I. \& Jensen, J.T. (eds) Museums Social learning Spaces and Knowledge Produsing Processes. Styrelsen. pp. 188-208.

5. Arnheim, R. (1974) Iskusstvo i vizual'noe vospriyatie [Art and Visual Perception]. Moscow: Progress.

6. Prokopenko, V.T., Trofimov, V.A. \& Sharok, L.P. (2006) Psikhologiya zritel'nogo vospriyatiya [The psychology of visual perception]. St. Petersburg: St. Petersburg ITMO University. 